\title{
Disassembly Evaluation in Design of a System Using a Multi-Parameters Index
}

\author{
Aslain Brisco Ngnassi Djami ${ }^{*}$, Wolfgang Nzié ${ }^{2}$, Serge Doka Yamigno ${ }^{3}$ \\ ${ }^{1} \mathrm{PhD}$ Candidate, National Advanced School of Agro-Industrial Sciences, University of Ngaoundere, Ngaoundere, Cameroon \\ ${ }^{2}$ Department of Basic Sciences and Techniques for the Engineer, EGCIM, University of Ngaoundere, Ngaoundere, Cameroon \\ ${ }^{3}$ Department of Physics, Faculty of Science, University of Ngaoundere, Ngaoundere, Cameroon \\ Email: ^ngnassbris@yahoo.fr, wnzie@yahoo.fr, numami@gmail.com
}

How to cite this paper: Ngnassi Djami, A.B., Nzié, W. and Doka Yamigno, S. (2020) Disassembly Evaluation in Design of a System Using a Multi-Parameters Index. Modern Mechanical Engineering, 10, 1-16. https://doi.org/10.4236/mme.2020.101001

Received: November 15, 2019

Accepted: February 16, 2020

Published: February 19, 2020

Copyright (c) 2020 by author(s) and Scientific Research Publishing Inc. This work is licensed under the Creative Commons Attribution International License (CC BY 4.0).

http://creativecommons.org/licenses/by/4.0/

\begin{abstract}
In order to help designers, consider disassembly in their design activities, a method for evaluation of product disassembly is proposed. Criteria characterizing the disassembility of a product are identified. Each criterion is assigned a coefficient, thus proposing an index of easy fixations $\left(I f_{f}\right)$ as a design indicator to evaluate the level of disassembly of a solution generated by the designer. This index is calculated as a weighted average of the indicators for evaluating the disassembility of the product. The proposed method uses information such as the list of subsets or parts, the component tree, the part geometry, the functional links between components and parts, the properties of the components. It has been tested on one product: the soy roaster.
\end{abstract}

\section{Keywords}

Design, Disassembly, Criteria, Evaluation Indicators

\section{Introduction}

With the awareness of sustainable development issues and the strengthening of the legislative framework relating to waste management and end-of-life product volumes, the urgency of putting in place development methods that are both efficient and effective, the economic plan, socially responsible and environmentally friendly becomes essential for designers. One of the strategies that is presented to the latter, is to design the products in a vision of reuse of components, recycling of materials and remanufacturing [1] [2]. This strategy involves product disassembly. In this context, designers are led to integrate earlier and earlier the constraints of disassembly of the product in the design process to ensure its disassembly (disassemblability). But how to define and evaluate the disassembly of 
a product? What are the steps to follow in order to integrate disassembility in the preliminary design phases? How to help the designer to choose a design solution that satisfies disassembly constraints?

In order to answer his questions, the following section presents a methodology for assessing the complexity of disassembly, followed by an application.

\section{Methodology for Assessing the Complexity of Disassembling}

The adopted methodology is described by the following flowchart (Figure 1).

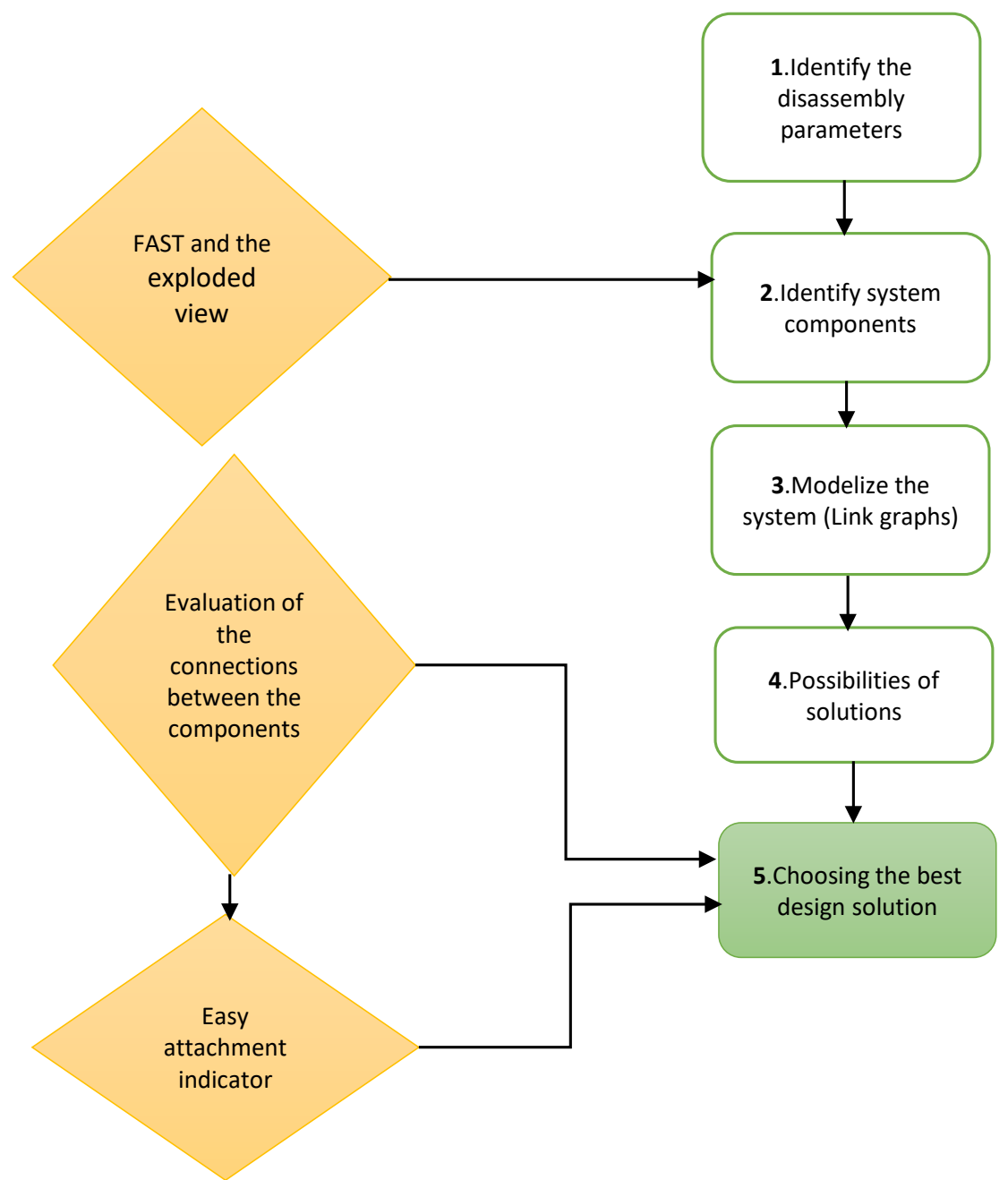

Figure 1. Description of the methodology.

\subsection{Choice of Disassembly Parameters}

The literature presents 14 parameters likely to represent all the problems encountered during this last phase of product life [1] [3]-[11].

Which is too important to be implemented directly. We will draw up a smaller list of parameters to best represent all facets of non-destructive disassembly of a product that can be used in its preliminary design phase. The list is as follows: 
- types of contacts;

- types of combinations;

- disassembly tools;

- number of disassembly directions;

- operator qualifications;

- required equipment.

A scale of values has been created for each parameter to calculate the disassembly complexity. The different values make it possible to represent the main possibilities and to classify them from the most interesting to the most restrictive. We will see these scales in detail and describe each of the values. To choose these scales of values, we mainly relied on three articles [12] [13] (see Tables $1-6)$.

Table 1. Types of contacts.

\begin{tabular}{cc}
\hline Types of contacts & Scale of value \\
\hline No contact & 1 \\
Punctual & 2 \\
Linear & 3 \\
Surface & 4 \\
Many points of contact & 5 \\
Many surfaces of contact & 6 \\
\hline
\end{tabular}

Table 2. Type of combinations.

\begin{tabular}{cc}
\hline Type of combinations & Scale of value \\
\hline To put & 1 \\
Insertion, screwing, riveting & 2 \\
Turn & 3 \\
Combine & 4 \\
Bonding, welding & 5 \\
\hline
\end{tabular}

Table 3. Disassembly tools.

\begin{tabular}{cc}
\hline Disassembly tools & Scale of value \\
\hline No & 1 \\
Compressed air tool & 2 \\
Mechanical tools & 3 \\
Supplied by the manufacturer & 4 \\
Specific & 5 \\
Improvised & 6 \\
\hline
\end{tabular}

Table 4. Number of disassembly directions.

\begin{tabular}{cc}
\hline Number of disassembly directions & Scale of value \\
\hline Above & 1 \\
\hline
\end{tabular}


Continued

\begin{tabular}{cc}
\hline On the sides & 2 \\
More than $15 \mathrm{~cm}$ deep & 3 \\
From below & 4 \\
Combined axes & 5 \\
Without visibility & 6 \\
\hline
\end{tabular}

Table 5. Operator qualifications.

\begin{tabular}{cc}
\hline Operator qualifications & Scale of value \\
\hline No & 1 \\
10 to 20 seconds & 2 \\
More than 30 seconds & 3 \\
Discussion & 4 \\
Training & 5 \\
\hline
\end{tabular}

Table 6. Required equipment.

\begin{tabular}{cc}
\hline Required equipment & Scale of value \\
\hline No & 1 \\
Gloves & 2 \\
Mask & 3 \\
Fire protection & 4 \\
Air filtration & 5 \\
Integral combination & 6 \\
\hline
\end{tabular}

We have studied different disassembly methods to determine a weighting for the above parameters and to see which ones are the most influential [12]. Weighting the parameters corresponds to giving more or less importance to a parameter. The sum of the weights is equal to 100 . The different alternatives will therefore be ranked on a scale of 0 to 100 and the higher the score, the more disassembly will be considered complex. The weights applied to the parameters are presented in Table 7.

Table 7. Weights of disassembly parameters.

\begin{tabular}{cc}
\hline Parameters & Weighting \\
\hline Number of disassembly directions & 30 \\
Disassembly tools & 25 \\
Types of contacts & 20 \\
Type of combinations & 15 \\
Operator qualifications & 5 \\
Required equipment & 5 \\
\hline
\end{tabular}


The most important weighting has been given to the number of directions and the disassembly tools, because they play an important role in the disassembly complexity because complex tools and certain disassembly directions can be very restrictive and limit the interest of a disassembly (disassemblability). The qualification of the operators and the equipment required were given smaller weightings, since these two parameters have less consequences on the difficulty of disassembly and the associated costs in comparison with the other parameters.

\subsection{Identification of the Different Components of the System}

The identification of the external environment and the formulation of the need of the system is done by means of the Octopus diagram or intersections graph. This diagram consists of the product, in the center, and around, elements of its environment (external environment). The relations (services functions $\mathrm{FP}_{\mathrm{i}}$ and $\mathrm{FC}_{\mathrm{i}}$ ) between the product and the external environment are shown. The structure of such a diagram is given in Figure 2.

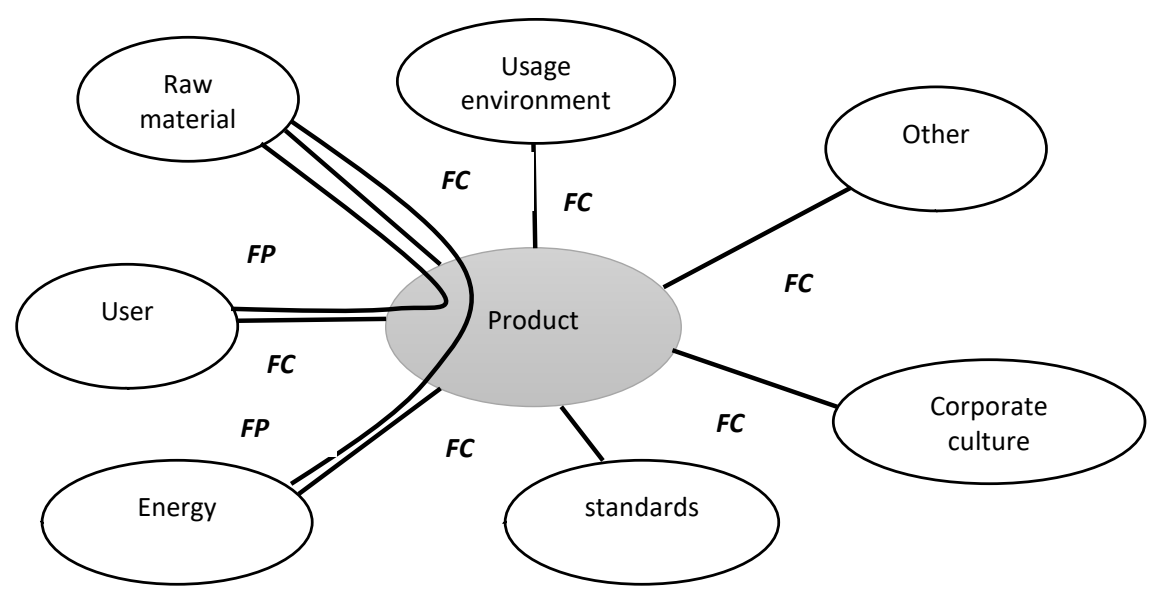

Figure 2. Structure of an octopus diagram.

The FAST (Function Analysis System Technique) will be developed, which from a service function will lead to the technical functions and associated constructive solutions. It details in several levels the realization of one or more service functions.

At the end of this FAST, an exploded view of the solution will be generated automatically and with the support of a legend that will provide a global vision of the system in terms of components.

\subsection{Link Graphs}

The Component Mating Graph (CMG) represents the product (system) at the component level. The nodes and arcs of this graph represent, respectively, the components and the bonds between the components [14] [15]. The links can be oriented or unoriented. Non-oriented links indicate the existence of a geometrical relation (contact stress) between two components such as planar or cylin- 
drical contact but also a contact caused by the different types of attachment such as screwing, snap adjustment (snap-fit), press fit. Oriented links refer to information of precedence (non-contact constraint) between two components such as information concerning accessibility to a disassembly task [16]. This modeling approach is illustrated in Figure 3.

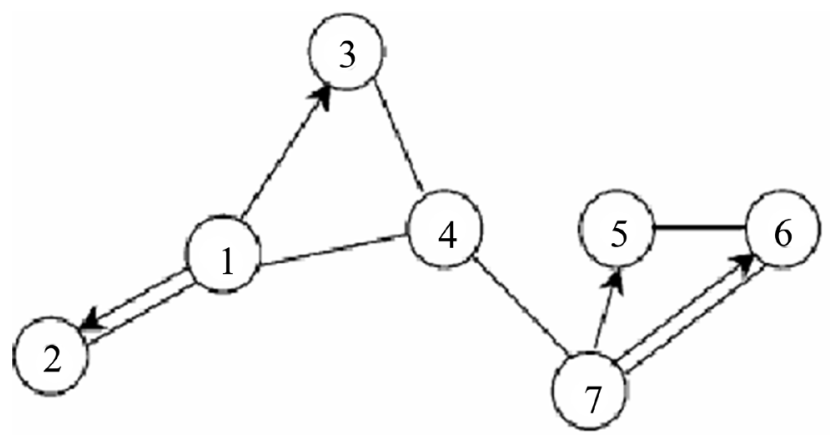

Figure 3. Hybrid link graph [16].

\subsection{The Possible Solutions}

For a given design that takes into account disassembly parameters, as presented above, several design solutions can be envisaged. Among these design solutions, there may be three types of solutions, those that are: good, unsatisfactory and satisfactory. The design solution is evaluated by means of an indicator (for example the index of easy attachments) which is a real number between 0 and $100 \%$. The closer it is to $100 \%$, the more the separability constraint is satisfied, the closer it is to $0 \%$ minus this constraint is satisfied [17]. Table 8 gives the satisfaction thresholds for the easy-fix indicator.

Table 8. The satisfaction thresholds of the easy bindings indicator.

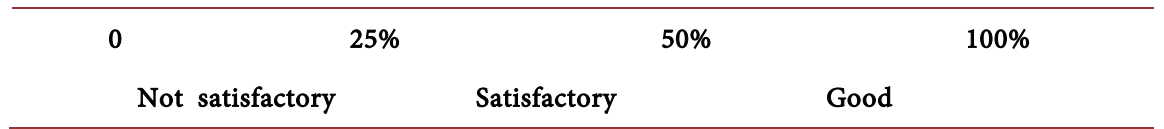

\subsection{Proposal for an Evaluation Indicator of the Design Solution}

Bibliographic synthesis of the design criteria for disassembly reveals six main criteria (identical fastener indicators, indicator of the number of components with identical materials, indicator of the weight of components with identical materials, indicator of the number of fasteners the same direction of access and indicator of easy fixations) [18] [19].

Of these indicators, the easy bindings indicator is the most relevant because it is the only one that takes into account the complexity of the disassembly movement. Indeed, the gesture to be made to undo an attachment influences the ease of disassembly, which is not taken into account by the other indicators. The disassembly parameters can therefore be qualified according to a predetermined scale. In order to qualify the parameters of disassembly, a weighting is proposed which increases with the difficulty to break the fixation considered by means of 
the coefficients which define the level of sophistication of these parameters [17] [18] [19].

However, the Easy Fixings Indicator proposed by the authors considers only three disassembly parameters: the type of tools, the number of disassembly or access directions, and the type of combinations or fasteners. Often, the disassembly of the product is too tedious to be put in place. Indeed, very often the one who performs the disassembly or assembly operation does not have personal protective equipment (e.g. gloves) to be able to remove the attachments of the product, which at any given time can lead to more time than expected. On the other hand, the lack of qualification of the operator to intervene on the product, can lead to a destructive disassembly (to the extent that the part is damaged during disassembly), this which could lead to recycling (thus generating additional costs) for future recovery of the damaged part. The time constraint is therefore a very important parameter because it is directly related to the cost of disassembly and thus obviously to the profitability of the disassembly operations. An assembly that is too long to disassemble will be much less interesting and disassembly may not be performed if it is really too important [10]. It is understood from this moment that for effective disassembly, it is more relevant to consider more than three parameters, so in the best case the six non-destructive disassembly parameters. The new indicator we propose that takes into account the six disassembly parameters mentioned above is given by the following formula:

$I f_{f}=\frac{\sum_{i=1}^{n}\left(A_{N D D} C N D D_{i}+A_{O D} C O D_{i}+A_{T C} C T C_{i}+A_{T C O} C T C O_{i}+A_{Q O} C Q O_{i}+A_{E R} C E R_{i}\right)}{n}$

with:

CNDD: complexity of disassembly directions,

$C O D$ : complexity of the disassembly tool,

$C T C$ : complexity of the type of contact,

$C Q O$ : complexity of the operators' qualification,

$C E R$ : complexity of required equipment,

$n$ : number of links involved,

$I f_{f}$ : Easy fixing indicator (in\%).

The complexity of the parameter considered in the link $i$ is given by the formula:

$$
C_{i}=a_{i} I_{i} p_{i}
$$

with:

$a_{i}$ : coefficient of the parameter representing the considered disassembly,

$I_{i}$ : value assigned to the disassembly parameter considered,

$p_{i}$ : weighting of the disassembly parameter considered.

It should be noted that the weighting of each disassembly parameter is already known, and the value assigned to each disassembly parameter will be extracted from the table of connections between the components of the system or product of study. Regarding the coefficient of the parameter representing the disassem- 
bly, the following tables will illustrate the calculation.

The terms $A_{N D D}, A_{O D}, A_{T C}, A_{T C O}, A_{Q O}$ and $A_{E R}$ are respectively the weights of the various factors of the indicator $I f_{f}$. Its latters are calculated as follows [17] [18] [19]:

$$
A_{i}=\frac{2(m+1-k)}{m(m+1)}
$$

with:

m: number of disassembly parameters considered (six for our formula),

$k$. number corresponding to the order of priority of the factors.

From the foregoing, the most significant weighting is given to the number of directions and the disassembly tools, and the least important is given to the qualification of the operators and the required equipment. Taking into account this order of priority, the assigned values of $k$ are given as follows:

$k=1$ for the number of disassembly directions,

$k=2$ for disassembly tools,

$k=3$ for the types of contacts,

$k=4$ for the types of combinations,

$k=5$ for the qualification of the operators,

$k=6$ for the required equipment.

The weights of the different factors are as follows:

$A_{N D D}=0.28 ; A_{O D}=0.23 ; \quad A_{T C}=0.19 ; \quad A_{T C O}=0.14 ; A_{Q O}=0.09 ; A_{E R}=$ 0.04 .

Following the approach proposed in [18] and [19], the coefficients associated with each disassembly parameter are given by the following tables (Tables 9-14) (the proposed weighting increases with the difficulty of breaking the fixation. considered):

Table 9. Example of the coefficients associated with the number of directions of access.

\begin{tabular}{cc}
\hline Number of disassembly directions & Coefficients \\
Above & $1 / 6$ \\
On the sides & $1 / 5$ \\
More than $15 \mathrm{~cm}$ deep & $1 / 4$ \\
From below & $1 / 3$ \\
Combined axes & $1 / 2$ \\
Without visibility & 1
\end{tabular}

Table 10. Example of coefficients associated with disassembly tools.

\begin{tabular}{cc}
\hline Disassembly tools & Coefficients \\
\hline No & $1 / 6$ \\
Compressed air tool & $1 / 5$ \\
Mechanical tools & $1 / 4$
\end{tabular}




\section{Continued}

Supplied by the manufacturer

Specific

Improvised

Table 11. Example of coefficients associated with types of contacts.

\begin{tabular}{cc}
\hline Types of contacts & Coefficients \\
\hline No & $1 / 6$ \\
Punctual & $1 / 5$ \\
Linear & $1 / 4$ \\
Surface & $1 / 3$ \\
Many point of contact & $1 / 2$ \\
Multi surface contact & 1 \\
\hline
\end{tabular}

Table 12. Example of the coefficients associated with the types of combinations.

\begin{tabular}{cc}
\hline Types of combinations & Coefficients \\
\hline To put & $1 / 5$ \\
Insertion, screwing, riveting & $1 / 4$ \\
Turn & $1 / 3$ \\
Combine & $1 / 2$ \\
Bonding, welding & 1 \\
\hline
\end{tabular}

Table 13. Example of the coefficients associated with the qualification of the operators.

\begin{tabular}{cc}
\hline Operator qualifications & Coefficients \\
\hline No & $1 / 5$ \\
10 to 20 seconds & $1 / 4$ \\
More than 30 seconds & $1 / 3$ \\
Discussion & $1 / 2$ \\
Training & 1 \\
\hline
\end{tabular}

Table 14. Example of the coefficients associated with the required equipment.

\begin{tabular}{cc}
\hline Required equipment & Coefficients \\
\hline No & $1 / 6$ \\
Gloves & $1 / 5$ \\
Mask & $1 / 4$ \\
Fire protection & $1 / 3$ \\
Air filtration & $1 / 2$ \\
Integral combination & 1
\end{tabular}




\section{Results}

This part illustrates the implementation of the disassembly complexity evaluation approach integrating the disassembly constraints, proposed in the previous section, on a product: the soy roaster.

With the large flow of raw materials (soybeans) to roast or roast, it turns out that it is more painful to do traditionally. Thus, by automating the roasting process, roasters are used which have the advantage of considerably reducing the time of roasting and energy loss. The creation of an octopus diagram (Figure 4) during the use of the roaster, identifies the environment outside the product and formulate the service functions (Table 15) it must meet.

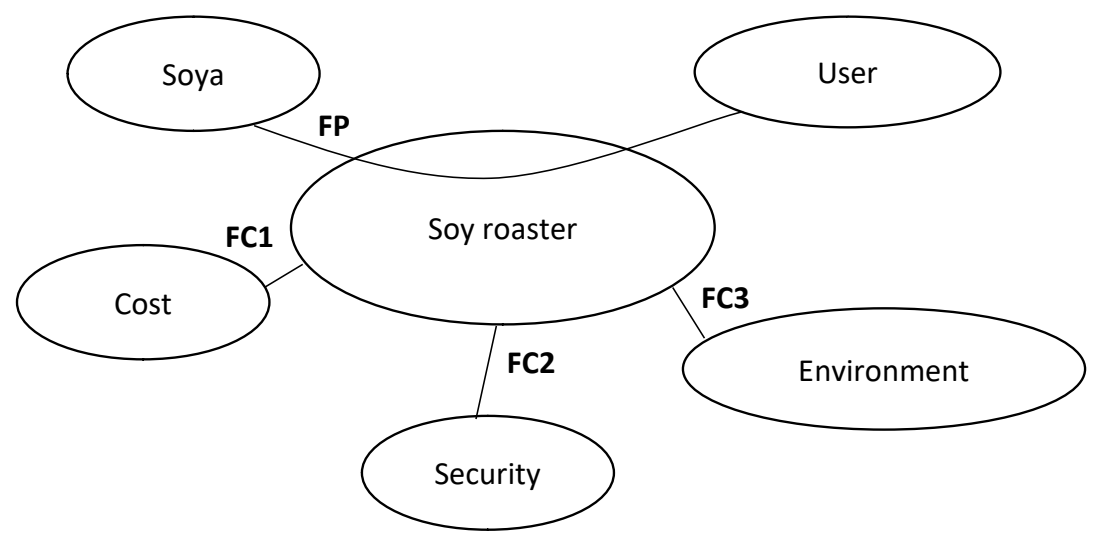

Figure 4. Octopus diagram of the soy roaster in use phase.

Table 15. Service functions.

\begin{tabular}{cc}
\hline FP & Allow the user to roast soy \\
\hline FC1 & To be easily accessible financially (minimum cost) \\
FC2 & Do not represent a danger for the user \\
FC3 & Must adapt to the environment \\
\hline
\end{tabular}

Recall that FP is the main function and FC is the complementary function.

\subsection{Identification of System Components}

\subsubsection{The FAST Diagram of the Soy Roaster}

The FAST (Function Analysis System Technique) of the soy roaster is given by Figure 5.

Following the functional analysis, based on the FAST we have identified the different technical functions to achieve the service function: "allow the user to roast the soy." We retained the technical functions:

- To put,

- To feed,

- To cool,

- To contain. 


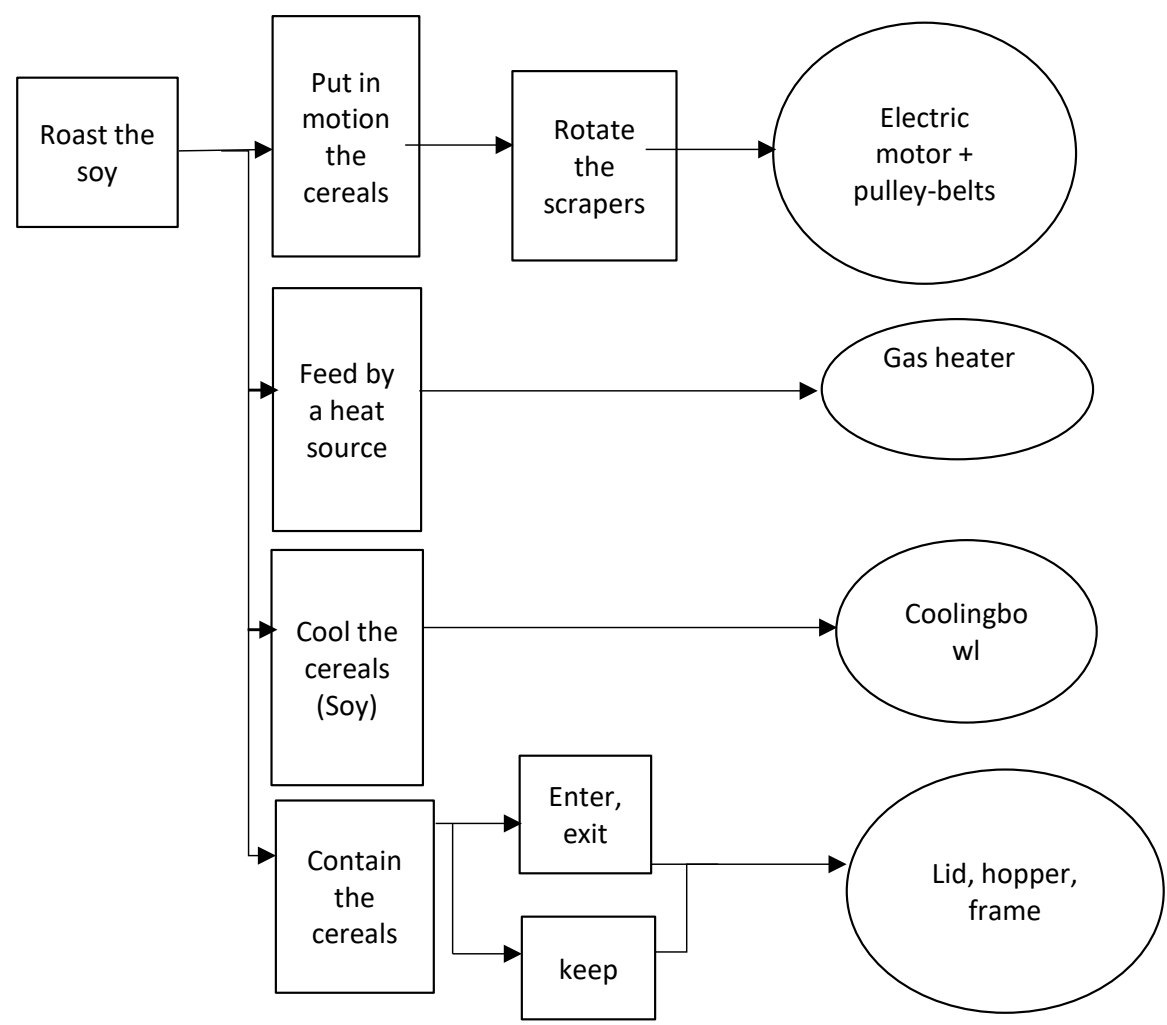

Figure 5. FAST relative to roasting function.

\subsubsection{Exploded View of the Soy Roaster}

The technical functions and technical sub-functions allowed us to detail the technological solutions. The soy roaster consists of 19 components as listed in Table 16. Figure 6 is an illustration of the product describing an exploded solution.

Table 16. Component legend.

\begin{tabular}{cc}
\hline Reference of components & Component names \\
\hline 1 & Frame \\
2 & Engine \\
3 & Belt \\
4 & Disc 2 (pulley) \\
5 & Main axis \\
6 & Main shaft bearing 1 \\
7 & Main shaft bearing 2 \\
8 & Engine side bearing bracket \\
9 & Motor disk \\
10 & Hood \\
11 & Bowl-side bearing support \\
12 & Bowl \\
\hline
\end{tabular}




\begin{tabular}{cc} 
Continued & \\
\hline 13 & Secondary axis \\
14 & Secondary axis bearing \\
15 & Secondary axle bearing support \\
16 & Output hopper \\
17 & Main cylinder \\
18 & Scraper \\
19 & Inlet hopper \\
\hline
\end{tabular}

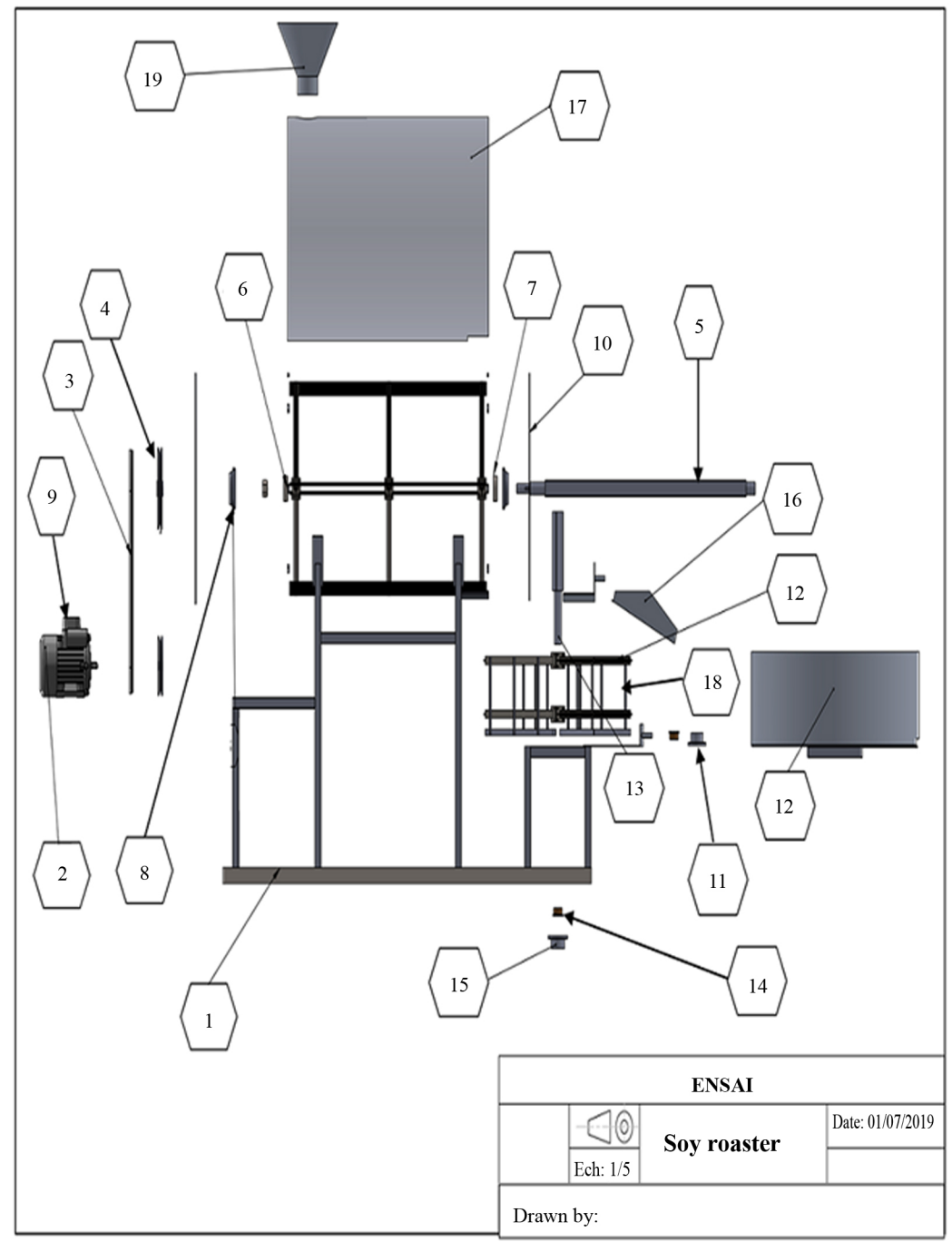

Figure 6. Exploded view of the solution.

\subsection{Modeling of the Product by the Link Graph}

The structure of the product makes it possible to construct the graph of the links presented in Figure 7. Indeed, having a global view of the product in terms of its constituents, thanks to the graph of laisons, it is possible to highlight the different possible reports between the components of the product. 


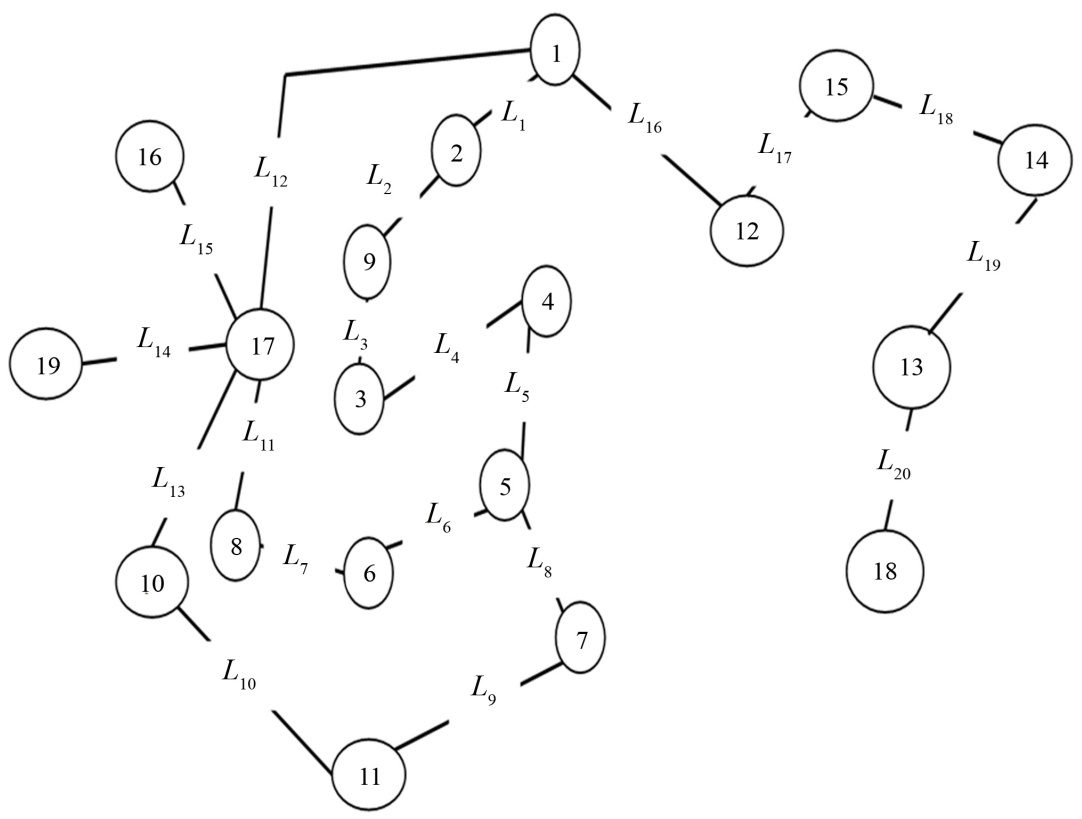

Figure 7. Link graph of soy roaster.

\subsection{Assessment of Disassembly Complexity}

As mentioned in the methodology, an index If $f_{f}$ (Equation (1)) is chosen as the design indicator to evaluate the disassembly complexity of a solution generated by the designer.

The disassembly complexity of the soy roaster is evaluated from six proposed parameters for two solutions whose characteristics are as follows:

- Solution 1: the roaster consists of two large sets: the upper set (main frame-cylinder) and the lower set (rack-bowl).

The upper set is subdivided into three parts. The first part consists of parts 1 , $17,19,10,16,11$ and 8 . The second part consists of parts 2, 3 and 9. The third part is composed of parts 4, 5, 6 and 7. The assembly between these three parts is provided by screw-nut system.

The lower set is subdivided into two parts. The first part consists of parts 1,14 and 15 . The second part is composed of parts 12,13 and 18 . The assembly between these two parts is provided by screw-nut system.

- Solution 2: this solution is similar to the previous one, the only difference is that parts 17 and 16 are welded.

Table 17 makes an evaluation of the connections between the components of the product.

Table 17. Evaluation of the bonds between the components.

\begin{tabular}{cccccccc}
\hline Connection & TC & OD & NDD & TCO & QO & ER & Value \\
\hline $1-2$ & 6 & 3 & 5 & 4 & 3 & 2 & 23 \\
$2-9$ & 4 & 1 & 4 & 3 & 1 & 1 & 14 \\
$3-9$ & 4 & 3 & 5 & 2 & 2 & 2 & 18 \\
\hline
\end{tabular}




\section{Continued}

\begin{tabular}{|c|c|c|c|c|c|c|c|}
\hline $3-4$ & 4 & 1 & 4 & 3 & 1 & 1 & 14 \\
\hline $4-5$ & 4 & 3 & 5 & 4 & 3 & 2 & 21 \\
\hline $5-6$ & 4 & 3 & 5 & 2 & 3 & 2 & 19 \\
\hline $5-7$ & 4 & 3 & 5 & 2 & 3 & 2 & 19 \\
\hline 6-8 & 6 & 1 & 5 & 2 & 2 & 2 & 18 \\
\hline $7-11$ & 6 & 1 & 5 & 2 & 2 & 2 & 18 \\
\hline $11-10$ & 4 & 3 & 5 & 4 & 3 & 2 & 21 \\
\hline $17-10$ & 6 & 3 & 5 & 2 & 2 & 2 & 20 \\
\hline $17-8$ & 4 & 3 & 5 & 4 & 3 & 2 & 21 \\
\hline $17-1$ & 6 & 3 & 5 & 4 & 3 & 2 & 23 \\
\hline $17-16$ & 6 & 3 & 5 & 4 & 3 & 2 & 23 \\
\hline $1-12$ & 6 & 3 & 5 & 4 & 3 & 2 & 23 \\
\hline $15-14$ & 4 & 3 & 4 & 2 & 2 & 2 & 17 \\
\hline $12-15$ & 4 & 3 & 5 & 4 & 3 & 2 & 21 \\
\hline $14-13$ & 4 & 3 & 5 & 4 & 3 & 2 & 21 \\
\hline $18-13$ & 4 & 3 & 5 & 4 & 3 & 2 & 21 \\
\hline $19-17$ & 4 & 3 & 5 & 4 & 3 & 2 & 21 \\
\hline
\end{tabular}

The easy fixing indices obtained for the two solutions proposed are of the order of $37.09 \%$ for solution 1 and $39.05 \%$ for solution 2. Both solutions belong to the interval $[25 \%, 50 \%]$ that reflect a satisfactory solution. But solution 2 has the index of easy fixations closest to $50 \%$, it is then considered as the design solution most respectful of disassembly constraints at the end of life than solution 2.

\section{Conclusion}

This paper is devoted to the application of a methodology for assessing the complexity of disassembly using a criterion of integration of disassembly at the end of life during the preliminary design phase. An evaluation of the design solutions of a soy roaster is presented, following which the choice of the design solution most respectful of disassembly constraints is carried out. These design parameters will be very useful for the deployment of the classification algorithm on the soy roaster.

\section{Acknowledgements}

The authors thank Ms Emma Liu for the technical support provided. We also thank the Mechanical Engineering Laboratory for contributions to this paper.

\section{Conflicts of Interest}

The authors declare no conflicts of interest regarding the publication of this paper. 


\section{References}

[1] Chen, R.W., Navin-Chandra, D. and Prinz, F.B. (1993) Product Design for Recyclability: A Cost Benefit Model and Its Application. Proceedings of the 1993 IEEE International Symposium on Electronics and the Environment, Arlington, 10-12 May 1993, 178-183.

[2] Millet, D., Brissaud, D. and Zwolinski, P. (2007) Design for Reuse, Remanufacture and Recycling: An Alternative to Design for Landfill. International Journal of Environmentally Conscious Design and Manufacture, 13.

[3] Desai, A. and Mital, A. (2003) Evaluation of Disassemblability to Enable Design for Disassembly in Mass Production. International Journal of Industrial Ergonomics, 32, 265-281. https://doi.org/10.1016/S0169-8141(03)00067-2

[4] Duflou, J.R., Seliger, G., Kara, S., Umeda, Y., Ometto, A. and Willems, B. (2008) Efficiency of Product Disassembly: A Case-Based Study. CIRP Annals-Manufacturing Technology, 57, 583-600. https://doi.org/10.1016/j.cirp.2008.09.009

[5] Ghazilla, R.A.R., Taha, Z., Yusoff, S., Rashid, S.H.A. and Sakundarini, N. (2014) Development of Decision Support System for Fastener Selection in Product Recovery Oriented Design. The International Journal of Advanced Manufacturing Technology, 70, 1403-1413. https://doi.org/10.1007/s00170-013-5373-3

[6] Güngör, A. (2006) Evaluation of Connection Types in Design for Disassembly (DFD) Using Analytic Network Process. Computers \& Industrial Engineering, 50, 35-54. https://doi.org/10.1016/j.cie.2005.12.002

[7] Haoues, N., Froelich, D. and Zwolinski, P. (2004) Disassembly for Valorisation in Conceptual Design. Environmentally Conscious Manufacturing IV, Vol. 5583, Philadelphia, 25-28 October 2004, 31-42. https://doi.org/10.1117/12.580434

[8] Jeandin, T. (2015) Choice of End-of-Life Attachments for Products. Master of Applied Sciences, Université de Montréal, Ecole Polytechnique De Montréal, Montréal, $122 \mathrm{p}$.

[9] Pak, K.G. and Sodhi, R. (2002) Destructive Disassembly of Bolts and Screws by Impact Fracture. Journal of Manufacturing Systems, 21, 316-324. https://doi.org/10.1016/S0278-6125(02)80170-4

[10] Rose, C.M., Ishii, K. and Masui, K. (1998) How Product Characteristics Determine End-of-Life Strategies. Proceedings of the 1998 IEEE International Symposium on Electronics and the Environment, Oak Brook, 4-6 May 1998, 322-327.

[11] Sonnenberg, M. (2001) Force and Effort Analysis of Unfastening Actions in Disassembly Processes. PhD Thesis, New Jersey Institute of Technology, Newark.

[12] Kroll, E. and Hanft, T.A. (1998) Quantitative Evaluation of Product Disassembly for Recycling. Research in Engineering Design, 10, 1-14. https://doi.org/10.1007/BF01580266

[13] Kroll, E. and Carver, B.S. (1999) Disassembly Analysis through Time Estimation and Other Metrics. Robotics and Computer Integrated Manufacturing, 15, 191-200. https://doi.org/10.1016/S0736-5845(99)00026-5

[14] Murayama, T., Oba, F., Abe, S. and Yamamichi, Y. (2001) Disassembly Sequence Generation Using Information Entropy and Heuristics for Component Replacement. Proceedings of the IEEE International Symposium, Fukuoka, 29 May 2001, 208-213.

[15] Zussman, E., Kriwet, A. and Seliger, G. (1994) Disassembly Oriented Assessment Methodology to Support Design for Recycling. Annals of the CIRP, 43, 9-14. https://doi.org/10.1016/S0007-8506(07)62152-0 
[16] Li, J.R., Khoo, L.P. and Tor, S.B. (2002) A Novel Representation Scheme for Disassembly Sequence Planning. International Journal Advanced Manufacturing Technology, 20, 621-630. https://doi.org/10.1007/s001700200199

[17] Said, H., Chekh-Waiss, P., Mitrouchev and Tollenaere, M. (2013) Indicators for Evaluating the De-Assembling of Products. 21st French Mechanics Congress, Bordeaux, 26-30 August 2013, Ref S7B144EU.

[18] Dowie, T.A. and Simon, M. (1994) Guidelines for Designing for Disassembly and Recycling. Department of Mechanical Engineering, Design and Manufacture, the Manchester Metropolitan University, Manchester.

[19] Bhamra, T.D. (1995) A Disassembly Planning and Optimisation Methodology for Design. Manchester Metropolitan University, Manchester. 